\title{
Portugal, PAÍ́S DE TURISMO: DISSONÂNCIAS E USOS TURÍSTICOS DO PATRIMÓNIO DO ESTADO NOVO
}

Belmira Coutinho, Maria Manuel Baptista, Moisés de Lemos Martins \& José Rebelo

\section{RESUMO}

Este artigo reflete sobre os usos, especialmente os turísticos, da herança patrimonial da ditadura em território português. Recorre à teoria do património dissonante e questiona o contributo que o enquadramento do turismo negro pode dar para a interpretação deste património.

\section{PorTUgAL, LAND OF TOURISM: DISSONANCES AND TOURISTIC USES OF THE ESTADO NOVO'S HERITAGE}

\begin{abstract}
This article presents a reflection on the uses of the heritage of Portuguese dictatorship, especially by tourism. It makes use of the theory of dissonant heritage and questions the contribution of dark tourism's theoretical framework for to the interpretation of this heritage.
\end{abstract}

KEYWORDS

Dark tourism; dissonant heritage; Estado Novo; museums of resistance

\section{INTRODUÇÃo}

A criação da Secção de Presos Políticos e Sociais, em 1934, fez com que a então chamada Polícia de Vigilância e Defesa do Estado (PVDE, mais tarde Polícia Internacional de Defesa do Estado - PIDE) passasse a administrar diretamente a cadeia do Aljube, em Lisboa, o Forte de Caxias, a Fortaleza de Peniche, a Fortaleza de São João Baptista, em Angra do Heroísmo, e, depois de 1936, o campo de concentração do Tarrafal, na ilha de Santiago (Cabo-Verde). Além destas, o Estado Novo tinha prisões políticas militares, ou prisões militares que acolheram presos políticos militares, como a Casa de Reclusão Militar da Trafaria, que funcionou no Forte de Nossa Senhora da Saúde da Trafaria (Caldeira, Rosas, Quintanilha, Pimentel \& Martins, 2011). A PIDE já possuía locais de detenção e interrogatório por todo o país, mas estes estabelecimentos vieram juntar-se às prisões privativas que funcionavam nas delegações de Coimbra e Porto (esta conhecida como o Aljube do Porto) e na diretoria em Lisboa, localizada na Rua António Maria Cardoso (Caldeira et al., 2011). 
Estes serão os sítios mais emblemáticos da repressão e da violência exercidos pelo Estado Novo. Todavia existem em Portugal muitos outros edifícios com fortes ligações ao aparelho repressivo e ideológico do Estado Novo.

Os Tribunais Plenários da Boa Hora, em Lisboa, e de São João Novo, no Porto foram criados com o intuito de julgarem os opositores ao Estado Novo. Na prática nada mais eram do que uma "instituição policial disfarçada" (Pacheco, 2006) através da qual o Estado condenava sumariamente os seus adversários políticos. Em Lisboa, existiram a sede do Governo de Salazar, na praça do Comércio, a sede da União Nacional (depois Acção Nacional Popular, o partido único do Estado Novo), a sede da Mocidade Portuguesa, a sede da Legião Portuguesa, o local onde funcionou o Secretariado de Informação, a residência de Salazar na Rua Bernardo Lima, a Escola da PIDE. No Estoril, o Forte de Santo António foi a residência de férias de Salazar.

Património como este está ligado a um passado contestado que contém elementos dissonantes e potencialmente desestabilizadores do sentimento de identidade das comunidades e até da nação (Logan \& Reeves, 2009; Macdonald, 2009; Tunbridge \& Ashworth, 1996), pelo que a sua gestão apresenta um conjunto específico de desafios para as sociedades em geral e para os gestores de património (Logan \& Reeves, 2009).

A reflexão sobre o património associado a um passado desconfortável para grupos ou nações contribui para desestabilizar premissas culturais e emaranhamentos sobre identidade e memória em diferentes tempos (Macdonald, 2009). Torna-se, portanto, importante refletir sobre ele de modo a evidenciar as dificuldades de representação e de receção pública (Macdonald, 2009). Este artigo procura contribuir para a reflexão sobre os usos do património herdado da ditadura em Portugal, com maior enfoque nos que envolvem o Turismo.

Embora existam já alguns estudos em Portugal sobre estes sítios a partir da perspetiva da museologia, não existe ainda uma análise que aborde a sua condição de património intrinsecamente dissonante e que explore a sua relação com o turismo de morte e de sofrimento. Para tal, começamos por discutir o conceito e a condição de património atribuída a estes locais, tendo por base a teoria do património dissonante de Tunbridge \& Ashworth (1996). A teoria do património dissonante transpõe para o património a noção de dissonância cognitiva da Psicologia, argumentando que também o património pode conter elementos que não são coerentes entre si. De seguida, apresentamos o conceito de Turismo Negro, aqui abordado como fenómeno complexo que engloba variados objetos e atores em locais que, pelas suas características, proporcionam aos visitantes uma relação com a morte e o sofrimento. Propomos que a abordagem deste tipo de turismo pode trazer um contributo relevante para a interpretação do património da ditadura em Portugal, ao incentivar à reflexão e reflexividade. Apresentamos depois a situação atual de algum do património mais reconhecível das instituições do Estado Novo, referindo os processos que conduziram ao uso atual dos edifícios, especialmente pelo turismo. Concluímos com a análise desses mesmos usos e processos à luz das teorias anteriormente apresentadas. 


\section{PATRIMónio DissonANTE}

O conceito de património tem vários significados. Começou por designar apenas uma herança ou os bens de família, até ser estendido para toda a produção cultural e artística de um grupo ou nação, chegando a confundir-se com o conceito de cultura (Silva, 2000; Tunbridge \& Ashworth, 1996). Atualmente, o património pode ser definido, de forma lata, como um legado do passado que transmitimos às gerações futuras (Silva, 2000).

No entanto, o conceito de património não equivale nem ao passado nem à cultura: ele é uma seleção e é um produto do presente. O processo de formação ou criação de património implica uma seleção, por parte da geração presente, dos aspetos ou elementos herdados do passado que deseja transmitir às gerações futuras (Silva, 2000; Tunbridge \& Ashworth, 1996): "trata-se de um processo simbólico de legitimação social e cultural de determinados objectos que conferem a um grupo um sentimento coletivo de identidade" (Silva, 2000, pp. 218-219).

Paralelamente ao processo de seleção de objetos a patrimonializar existe um processo de exclusão. Esta pode acontecer quando o património existente já não está de acordo com as diretivas atuais, ou seja, quando tem mensagens contraditórias que são dissonantes no contexto das normas prevalecentes ou da ideologia dominante (Logan \& Reeves, 2009; Tunbridge \& Ashworth, 1996). Tunbridge e Ashworth (1996) referem ainda a existência de uma deserdação. O processo de criação de património vai inevitavelmente excluir "grupos sociais, étnicos ou regionais" cujas experiências são "marginalizadas, marginalizadas, distorcidas, ou ignoradas" (Tunbridge \& Ashworth, 1996, p. 29).

Este processo é comum a todo o património, porém pode ser agravado no património ligado a um passado que os grupos ou nações reconhecem como significativo mas que permanece "contestado e incómodo para a reconciliação pública com uma identidade contemporânea positiva e auto-afirmativa" (Macdonald, 2009, p. 1). É o caso do património ligado a regimes políticos e/ou judiciais repressivos e violentos:

uma variedade de lugares, sítios e instituições representam o legado destes períodos dolorosos: sítios de massacres e genocídios, lugares relacionados com prisioneiros de guerra, prisões políticas e civis, e locais de internamento "benevolente" tais como lazaretos e manicómios. Estes locais trazem-nos vergonha agora pela crueldade e pela futilidade dos eventos que ocorreram dentro deles e as ideologias que representavam. Cada vez mais, porém, estão agora a ser vistos como "património". (Logan \& Reeves, 2009, p. 1)

Estes locais podem ter funções políticas e ser usados para servir os interesses de governos e outros grupos, sendo frequentemente usados para fortalecer ou mesmo formar identidades nacionais. Logan e Reeves (2009) referem que esta utilização pode chegar ao ponto do revisionismo ou distorção consciente não só das histórias dos locais e do património, mas também da memória coletiva:

uma distorção estrategicamente direcionada à manipulação do coletivo através da manipulação da sua história, ao "explicar" a sua história de 
forma a ganhar apoio para um conjunto específico de políticas destinadas à manutenção do seu poder hegemónico na ordem social presente. (Logan \& Reeves, 2009, p. 2)

Segundo Logan e Reeves (2009), isto é algo que acontece com frequência nos nacionalismos, mas também é comum nas sociedades pós-coloniais, fruto da necessidade de obter coesão política e social.

A destruição e a profanação deste património são também muito comuns (Forest \& Johnson, 2001). Por vezes existe um esforço no sentido de apagar ou esconder a associação de edifícios ligados a determinados regimes políticos e ordens sociais através da sua destruição ou descaracterização (Macdonald, 2009). A este esforço junta-se o da desmitificação dos locais por meio da conversão em locais de uso diário (Macdonald, 2009). A autora dá como exemplo o caso de Nuremberga, cujos habitantes julgaram que o facto de a cidade ser conhecida pelo complexo do Congresso do Partido Nacional-Socialista (Reichsparteitagsgelände) lá construído apagava todos os outros aspetos históricos da cidade ao mesmo tempo que representava um risco de a cidade se tornar local de peregrinação para neonazis. Por tais motivos as entidades públicas levaram a cabo intervenções de descaracterização dos edifícios no pós-guerra, até ter havido uma viragem da opinião pública nos anos 70 que obrigou a nova intervenção para a reconversão do complexo. Desde então a cidade encetou esforços para restaurar alguns dos edifícios do complexo e terminar a construção de outros, criando até o Centro de Documentação do Congresso do Partido Nacional-Socialista. Este foi instalado numa das alas do inacabado Centro de Congressos e além de funcionar como centro de documentação e fórum educativo sobre o Terceiro Reich alberga também a exposição Fascínio e Terror, que oferece um olhar sobre "as causas, o contexto e as consequências do regime de terror Nacional-Socialista"'.

Por vezes a comunidade local tem dificuldades em aceitar que aquele património ou aquele aspeto do seu passado tem interesse nacional ou internacional (Logan \& Reeves, 2009). Os autores referem que a interação com a comunidade local é fundamental, bem como o "reconhecimento de que o contexto em que os profissionais trabalham é político" (Logan \& Reeves, 2009, p. 13).

Embora haja autores que classificam este património como "difícil" (Macdonald, 2009), consideramos que todo o património é, por definição, pleno de tensões e dificuldades. Tunbridge e Ashworth (1996) introduziram a ideia de que todo o património possui elementos dissonantes.

O conceito de património dissonante inspirou-se na teoria desenvolvida por Festinger (1957) da dissonância cognitiva. Esta teoria, nascida na Psicologia, diz em linhas gerais que os indivíduos necessitam de obter coerência entre as suas cognições, havendo um conflito ou dissonância quando existem pelo menos dois elementos (crenças, opiniões, comportamentos) que não são coerentes (Festinger, 1957). Da mesma forma, a dissonância no património "envolve uma discordância ou falta de acordo e 
consistência" (Tunbridge \& Ashworth, 1996, p. 20) entre os seus elementos. Esta dissonância pode ser de várias ordens: em aspetos de mercantilização e marketing, no conteúdo das mensagens transmitidas pela interpretação, e nas próprias atitudes das sociedades sobre e para com determinado património. A dissonância é intrínseca ao património, ou seja, faz parte da sua natureza, não podendo ser removida. É também universal no sentido em que é uma condição que todo o património possui, embora com intensidades muito diferentes.

Para Tunbridge e Asworth (1996) existe um tipo particular de património cujas características potenciam a dissonância: o património da atrocidade, em que a dissonância pode provocar emoções intensas e ter ligações a memórias que provocam mudanças profundas na autoimagem ou identidade dos povos. Os autores definem a atrocidade como "atos de singular crueldade" e "especialmente chocantes" perpetrados por pessoas contra pessoas (Tunbridge \& Ashworth, 1996, p. 95), salvaguardando todavia que ambos os elementos podem estar presentes em diferentes graus de intensidade.

\section{O TURISMO EM LUGARES DE MORTE E DE SOFRIMENTO}

A atração por lugares de morte e de sofrimento está presente na humanidade desde que as pessoas são capazes de se deslocar (Sharpley, 2009). A maior facilidade de divulgação dos acontecimentos e dos locais de morte e de sofrimento trazida pelo desenvolvimento dos meios de comunicação fez com que o interesse turístico nestes locais crescesse e a atividade turística se desenvolvesse (Logan \& Reeves, 2009; Sharpley \& Stone, 2009; Walter, 2009).

O conceito de turismo negro designa a atividade turística em locais que, acidental ou intencionalmente, são atrações turísticas e que têm ligações concretas e identificáveis a episódios ou situações de morte e de sofrimento. O turismo negro exibe simbolicamente a morte do Outro nas suas atrações. Estas assumem-se como locais onde a mortalidade contemporânea é reconfigurada e revitalizada, mediando assim a complexidade da morte e potenciando uma reflexão sobre a morte do Eu (Stone, 2011).

Stone (2011) identificou quatro motivos que explicam o papel do turismo negro enquanto mediador da morte na sociedade contemporânea. $O$ primeiro é o facto de o turismo negro representar e comunicar a morte. $O$ segundo motivo apontado pelo autor é o facto de o turismo negro dar ao visitante a oportunidade de acumular "capital da morte", que pode depois usar quando precisar de refletir sobre ela. O facto de os locais de turismo negro constituírem locais onde a mortalidade contemporânea é reconfigurada e revitalizada, mediando assim a complexidade da morte, é o terceiro motivo. $\mathrm{O}$ último motivo mencionado por Stone (2011) é o facto de o turismo negro mediar o que é aparentemente macabro ao exibir simbolicamente a morte.

Este papel de mediação tem uma particular importância nesta época descrita por Martins (2002) como a era mediática, na qual os rituais da celebração da morte deixaram de mediar a passagem "entre esta vida e a outra" (Martins, 2013, p. 113) e os média nos apresentam morte em direto sem qualquer ritual a mediar a passagem. 
Os locais de turismo negro são lugares de memória (lieux de mémoire, Nora, 1993) que fomentam o sentido de ligação de um grupo com o seu passado, abraçando memórias coletivas sociais traumáticas, relacionando vida e morte, e apresentando um tempo passado que fica ou deve ficar como símbolo (Logan \& Reeves, 2009). Neste sentido, constituem-se como heterotopias (Foucault, 1984): espaços físicos e sociais onde a normalidade é interrompida e onde são projetados significados relacionados com o local, aquilo que representa, e o indivíduo que o visita (Stone, 2013). São sítios onde a cultura local é refletida e simultaneamente ultrapassada, permitindo aos visitantes refletir sobre crises presentes e futuras com significado supranacional. Desta forma, estes locais representam mais do que um único momento no passado, apontando antes para uma justaposição de tempos (Stone, 2013).

As atrações de turismo negro estão relacionadas com a morte e com o sofrimento em diferentes graus de intensidade. Miles (2002) atribui essas diferenças a fatores espaciais e temporais, que demonstra com os exemplos do Museu do Memorial do Holocausto em Washington e do campo de concentração de Auschwitz-Birkenau. Para Miles (2002), o turismo praticado em Auschwitz-Birkenau possui uma relação mais intensa com a morte e com o sofrimento do que o turismo praticado no Memorial do Holocausto porque o primeiro é um local de morte e de sofrimento reais enquanto no segundo apenas existe a associação ou alusão a morte e a sofrimento que ocorreram noutros sítios. Por seu lado, os fatores temporais influenciam a intensidade de relação dos lugares com a morte e o sofrimento uma vez que as situações de morte e sofrimento que fazem parte da memória de primeira geração ou que podem ser validados por testemunhas vivas criam maior empatia (Miles, 2002).

Stone (2006) condensa a sua visão sobre as intensidades do turismo negro num espetro de intensidades da oferta desse tipo de turismo (Figura 1).

Os extremos deste espectro são o turismo negro mais claro e o turismo negro mais escuro.

O turismo negro mais claro compreende locais que foram concebidos de raiz como atrações turísticas e exploram uma associação à morte e ao sofrimento com vista ao entretenimento. Por isso têm pouca influência política e ideológica. Ao centrarem-se em eventos ou situações de morte e de sofrimento mais antigos terão também menor carga emocional. São locais dotados de uma forte infraestrutura turística que promove o consumo de um produto turístico construído em torno de apresentações ou representações romantizadas e mercantilizadas da morte e do sofrimento.

O turismo negro mais escuro decorre em lugares de morte e de sofrimento reais e temporalmente mais próximos que recebem atividade turística com vista à educação. A presença física dos edifícios torna mais difícil o esquecimento e convida à comemoração e reflexão, sendo por isso parte integrante da sua identidade museológica e interpretativa (Macdonald, 2009). Estes locais têm foco na conservação dos espaços e na preservação das memórias. As infraestruturas de apoio à atividade turística são apenas as consideradas essenciais e na maioria dos casos adicionadas a posteriori. 


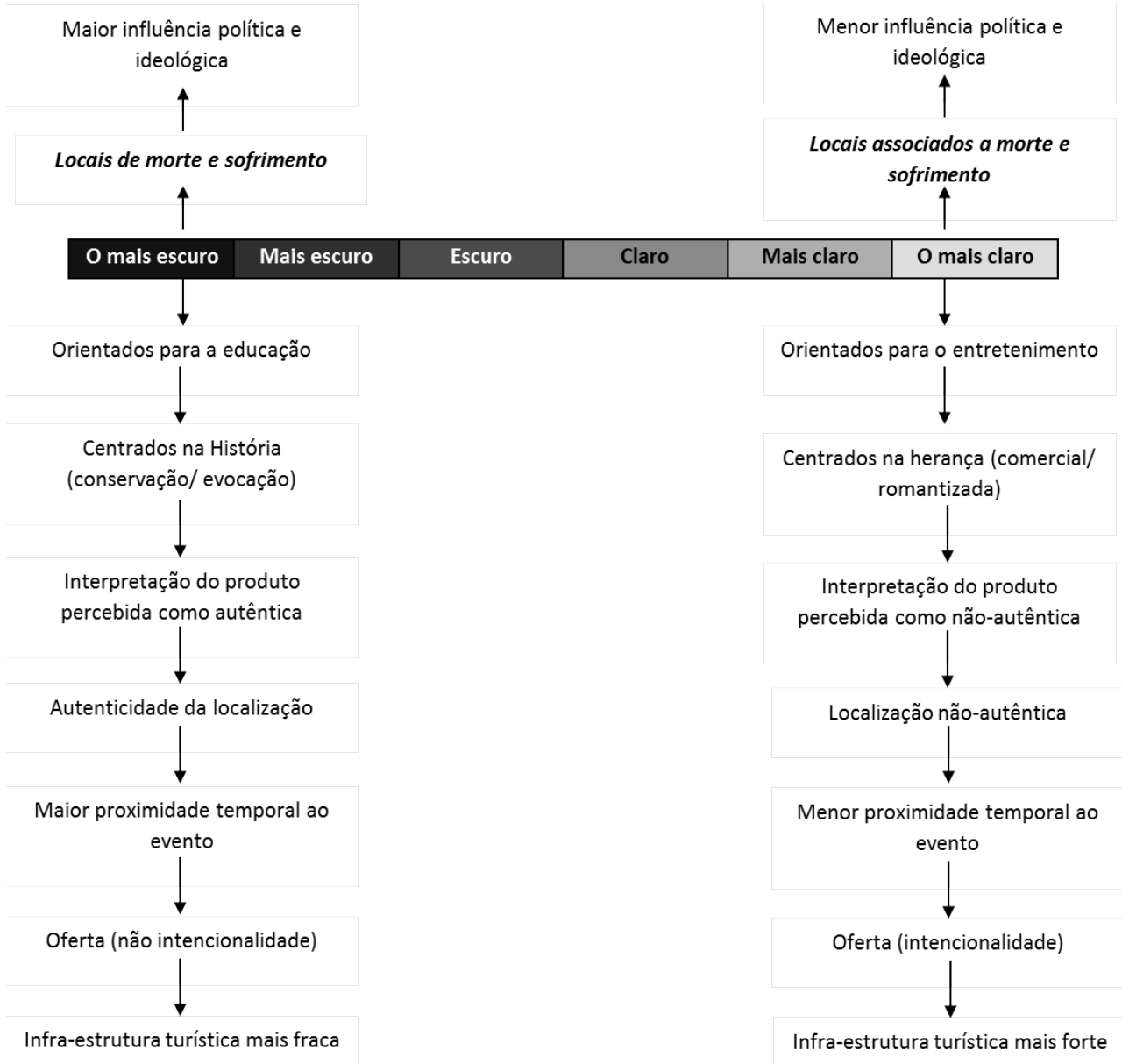

Figura 1: Espectro de tonalidades da oferta turística de Stone

Fonte: adaptado de Stone, 2006

Os locais de turismo negro mais escuro tendem a possuir uma maior carga simbólica e a estar sujeitos a maior influência política e ideológica, já que os acontecimentos ou situações de morte e de sofrimento de que foram palco costumam ter uma forte relação com regimes políticos e questões sociais (Macdonald, 2009; Stone, 2006). Duffy (2001) classifica estes lugares em subtipologias: museus de memória, museus do Holocausto e genocídios, museus de escravatura e de comércio de escravos, museus de direitos civis afro-americanos, museus de prisão, e museus de tortura. Williams (2007) acrescenta temas mais específicos: terrorismo, acidentes nucleares e outras formas de conflito irregulares. Estas classificações são bastante limitativas na sua aplicabilidade a diferentes contextos culturais, por exemplo os de países que passaram por regimes políticos opressivos e/ou ditatoriais. Torna-se necessário incluir nestas categorizações os museus de resistência e outros museus, centros de interpretação, ou memoriais que materializem estes passados traumáticos.

Todos esses espaços de eventos traumáticos que se tornam alvo de atividade turística têm temáticas variadas, locais diversificados e missões individuais, contudo possuem determinadas características em comum, segundo Williams (2007). A primeira delas é 
o facto de estarem habitualmente vinculados a eventos políticos relevantes, como por exemplo dias memoriais. Os museus e centros de interpretação costumam também ter uma forte missão pedagógica que inclui uma componente psicossocial no trabalho com sobreviventes, e o trabalho educativo procura estabelecer ligações com questões problemáticas da atualidade (Williams, 2007). Além disso, é comum que muitos destes museus estejam ligados a comissões de verdade e reconciliação e a organizações de direitos humanos e muitas vezes existe um grupo de pessoas com uma relação especial com os museus, por exemplo membros da resistência e familiares e amigos das vítimas ou até dos perpetradores.

O período das guerras no século XX fez com que vários grupos de pessoas se quisessem ver representados no espaço público e se envolvessem no trabalho memorial (Ray, 2006). Estes "empreendedores de memória" (Macdonald, 2009) empenham-se em proteger direitos civis, minorias culturais e políticas e diferenças de classe, religiosas e sexuais através da comemoração/memorialização de eventos ou situações de morte e de sofrimento de que foram vítimas.

\section{O património do Estado Novo na ATUALIdAde}

$\mathrm{Na}$ atualidade, os usos dados ao património do Estado Novo são bastante diversos. Há edifícios devolutos, outros restaurados, outros em uso ininterrupto e até alguns casos em que os lugares foram memorializados graças à intervenção de grupos de cidadãos. De seguida apresentamos o que sucedeu e a utilização atual de alguns dos edifícios mais emblemáticos do aparelho ideológico e repressivo do Estado Novo.

A sede da polícia Nacional de Defesa do Estado, na Rua António Maria Cardoso, em Lisboa, é um caso paradigmático da gestão do património do Estado Novo em Portugal. Alugado à Casa de Bragança, o imóvel foi-se degradando progressivamente depois de 1974, sendo gerido pela Assembleia da República. O aluguer terminou em 1990, e em 2005 o edifício foi vendido a um grupo de investimento privado, que o recuperou e transformou em condomínio fechado. Isto aconteceu apesar dos vivos protestos de grupos de cidadãos, que estiveram na origem da formação do NAM. Em 1980, por iniciativa de um grupo de cidadãos, foi adicionada uma placa comemorativa das quatro pessoas mortas por agentes da PIDE a 25 de Abril de 1974. Esta foi várias vezes substituída: "nas obras para o condomínio, a placa desapareceu, houve protestos, a placa voltou, em 2014 foi roubada, fizeram-se queixas e voltou em réplica" (Alves, 2017).

A cadeia do Aljube, em Lisboa, é hoje o Museu do Aljube: Resistência e Liberdade. Após o encerramento do estabelecimento prisional por falta de condições, em 1965, o edifício sofreu obras de melhoramento, porém não chegou a retomar o funcionamento. Depois do 25 de Abril o Aljube permaneceu sob tutela do Ministério da Justiça, que lá instalou diversos serviços, o que exigiu obras de conversão do imóvel (Martins, 2015). No início da década de 1990 surgem as primeiras indagações oficiais sobre a possibilidade de lá se estabelecer um museu de resistência (Oliveira, 2012), o que só se veio a concretizar em 2015. Este museu é tutelado pela Câmara Municipal de Lisboa e gerido 
por uma empresa municipal (a EGEAC - Empresa de Gestão de Equipamentos e Animação Cultural).

Disposta por quatro pisos térreos e um subterrâneo, a exposição permanente do Museu do Aljube começa por contar a história patrimonial do edifício para depois apresentar o regime fascista português e contextualizá-lo face aos seus congéneres. Passa então a detalhar as diversas formas de opressão e resistência durante a ditadura em Portugal e nos países anteriormente ocupados por este, culminando com a vitória da democracia e a Revolução de 25 de Abril de 1974. A exposição contém também secções dedicadas aos relatos de tortura e sofrimento dos presos e detidos políticos pelo Estado Novo, com uma recriação das celas de isolamento (os "curros") e o mapeamento das diversas prisões e campos de concentração de que o regime se servia².

Além da exposição permanente, o Museu do Aljube acolhe exposições temporárias relacionadas com a resistência antifascista e possui um Serviço Educativo e um Centro de Documentação3.

O edifício que albergou a delegação da PIDE em Coimbra teve várias utilizações após o 25 de Abril: foi a delegação de Coimbra do Serviço de Coordenação da Extinção da PIDE/DGS, depois sede da Direção Regional de Educação do Centro, e uma extensão do Centro de Saúde de Celas (Alves, 2017). Propriedade da mesma família desde o fim dos anos 40, o imóvel foi posto à venda em 2013, já depois de ter sido desocupado pela extensão de saúde. Esta intenção de venda foi alvo de indignação popular e de várias figuras públicas que por lá passaram, que defendiam a construção de um museu da memória da resistência ao fascismo (Sede da PIDE à venda por dois milhões de euros, 2013). A venda não foi concretizada, mas a conversão em museu também não. O edifício, totalmente recuperado, é hoje um hostel, o Luggage Hostel \& Suites. Apesar de a página da internet do hostel não fazer qualquer menção ao seu passado, um dos proprietários refere, em entrevista à revista Sábado, que se mantiveram as celas, as quais podem ser visitadas pelos hóspedes (Alves, 2017).

O complexo de edifícios chamado de Fortaleza ou Forte de Peniche é classificado como Monumento Nacional desde 1938, sendo propriedade do Estado4. Foi originalmente destinado a funções militares, servindo como prisão a partir do séc. XX. Enquanto prisão política tornou-se símbolo de opressão e de resistência e foi palco de algumas das fugas mais notáveis do sistema prisional português (Caldeira et al., 2011). Após a libertação dos presos políticos em 1974 chegou a acolher famílias de retornados. Em 1984 estabeleceu-se o Museu Municipal de Peniche numa parte do complexo e, mais tarde, o Estúdio Municipal de Dança e o Atelier Local de Artes, todos da responsabilidade da Câmara Municipal de Peniche5. O Museu Municipal incluía espaços dedicados à história e à produção cultural do município de Peniche e à história do próprio Forte, bem como

\footnotetext{
${ }^{2}$ Retirado de https://www.museudoaljube.pt/exposicao-permanente/

${ }^{3}$ Retirado de https://www.museudoaljube.pt/sobre-o-museu/

${ }^{4}$ Retirado de http://www.monumentos.pt/Site/APP_PagesUser/SIPA.aspx?id=4063

${ }^{5}$ Retirado de http://www.cm-peniche.pt/Cultura--Rede-Museologica--Museu-Municipal-de-Peniche
} 
o núcleo da resistência antifascista. Este núcleo ocupava várias secções da Fortaleza e tinha recriações da vida quotidiana dos presos nas celas de alta segurança, além de outra informação turística sobre a prisão política ${ }^{6}$.

O museu encontra-se atualmente encerrado para que se realizem as obras de instalação do Museu Nacional da Resistência e Liberdade7. A criação deste museu foi possível devido à contestação popular, já que em 2016 a Fortaleza foi integrada pelo Governo numa lista de monumentos que seriam concessionados a privados - programa REVIVE ${ }^{8}$.

A delegação da PIDE no Porto, chamada de Aljube do Porto, estava instalada numa residência familiar oitocentista e acolhe hoje o Museu Militar9. A génese deste museu data dos finais da década de 50 do século passado, ainda durante a ditadura e pensado para outro local da cidade do Porto, porém só em 1980 ele foi inaugurado ${ }^{10}$. O museu é dedicado à história militar portuguesa, tendo várias "salas de exposições dedicadas a miniaturismo, uniformes, peças de armamento ligeiro e artilharia pesada, e espaços dedicados a acontecimentos político-militares que ocorreram na cidade do Porto" ".

A Fortaleza de São João Baptista tem sido usada ininterruptamente pelo Exército Português desde $1643^{12}$. O Regimento de Guarnição n. ${ }^{\circ} 1$, uma unidade militar criada em 1993, é quem ocupa atualmente estas instalações. A Fortaleza está classificada como Imóvel de Interesse Público em conjunto com a igreja adjacente e inscrita no Centro Histórico de Angra do Heroísmo, Património Mundial da Unescodesde 1983 $3^{13}$. Está aberta a visitas do público. Existe uma lápide que assinala a presença de presos políticos no Forte de São João Baptista "na parede de uma instalação camarária junto a um parque, na estrada que dá acesso ao Forte"14, cuja colocação resultou da iniciativa da URAP (União de Resistentes Antifascistas Portugueses) e da Câmara Municipal de Angra do Heroísmo.

A prisão no Forte de Caxias albergou homens e mulheres acusados de crimes políticos durante o Estado Novo. Após ter sido desativado com a Revolução em 1974, o complexo permaneceu sem utilização até ser cedido à ex-Direcão-Geral dos Serviços Prisionais em 1988, funcionando desde então como um estabelecimento prisional de alta segurança ${ }^{15}$.

\footnotetext{
${ }^{6}$ Retirado de http://www.cm-peniche.pt/Cultura--Rede-Museologica--Museu-Municipal-de-Peniche

${ }^{7}$ Retirado de http://www.cm-peniche.pt/Cultura--Rede-Museologica--Museu-Municipal-de-Peniche

${ }^{8}$ Retirado de http://www.monumentos.pt/Site/APP_PagesUser/SIPA.aspx?id=4063

9 Retirado de http://www.patrimoniocultural.gov.pt/pt/museus-e-monumentos/ rede-portuguesa/m/museu-militar-do-porto/

${ }^{10}$ Retirado de http://www.patrimoniocultural.gov.pt/pt/museus-e-monumentos/ rede-portuguesa/m/museu-militar-do-porto/

"Retirado de https://www.explorebonfim.com/museumilitardoporto

${ }_{12}$ Retirado de http://assets.exercito.pt/SiteAssets/RG1/Síntese Histórica.pdf

${ }^{13}$ Retirado de http://whc.unesco.org/en/list/206

${ }^{14}$ Retirado de http://www.urap.pt/index.php/actividade-mainmenu-29/ notcias-mainmenu-35/631-homenagem-aos-presos-politicos-em-angra-do-heroismo

${ }^{15}$ Retirado de https://justica.gov.pt/Justica-Criminal/Servicos-de-execucao-das-penas/

Area-territorial-alargada-do-tribunal-de-execucao-de-penas-de-Lisboa/Estabelecimento-Prisional-de-Caxias\#Caractersticas
} 
O Tribunal de São João Novo continua em funcionamento como tribunal, apesar de se encontrar em estado de degradação (Tribunal de São João Novo no Porto está a cair, 2018). O Tribunal Plenário da Boa Hora, em Lisboa, funcionou no Convento da Boa Hora, o qual está incluído na classificação da Lisboa Pombalina ${ }^{16}$. Este edifício permaneceu propriedade integral da Câmara Municipal de Lisboa até ser parcialmente comprado pelo Ministério da Justiça em 2012 ${ }^{17}$. A Câmara Municipal de Lisboa irá instalar, na parte que lhe pertence, uma escola básica (Simões, 2016). No imóvel principal, propriedade do Ministério da Justiça, estava previsto instalar o Centro de Estudos Judiciários, o Museu do Judiciário e serviços do Instituto de Registos e Notariado ${ }^{18}$. Contudo, as mais recentes notícias dão conta que aí se venha a instalar o Tribunal da Relação de Lisboa (Agência Lusa, 2018a).

O Forte de Nossa Senhora da Saúde da Trafaria encontra-se atualmente devoluto, sendo propriedade da Câmara Municipal de Almada'9 ${ }^{9}$. Não são conhecidos quaisquer planos para o local. Em 2016 realizaram-se neste espaço três exposições, incluindo uma intitulada "O Presídio e a Trafaria 450 anos de História" (Belo, 2016). O Forte de Santo António da Barra, no Estoril, era a casa de férias de Salazar e o local onde se deu a queda que veio a resultar na sua morte ${ }^{20}$. Trata-se de um edifício com valor histórico e patrimonial que não obstante permaneceu abandonado até ao presente ano ${ }^{21}$. $\mathrm{O}$ estado de degradação do local foi denunciado várias vezes nos meios de comunicação. Após uma reportagem da RTP (Ferreira, 2018) no início de 2018 o Ministério da Defesa optou por ceder a exploração do edifício à Câmara Municipal de Cascais, que procedeu à sua recuperação e o abriu a visitas (Agência Lusa, 2018b).

O edifício onde estava localizado o escritório de Salazar enquanto foi presidente do Conselho de Ministros, no Terreiro do Paço, em Lisboa, serviu mais tarde como esquadra de polícia e foi ocupado pelo Ministério da Administração Interna (Alves, 2017). Em 2015, após obras de reabilitação, nasceu neste local a Pousada de Lisboa, um luxuoso estabelecimento hoteleiro (Chaves, 2015).

Num artigo da revista Sábado (Alves, 2017) são mencionados mais dois exemplos. Em Montalegre, o antigo centro de detenção da polícia política foi usado como Centro de Saúde antes de ser convertido em hotel, sendo atualmente ocupado pelo Montalegre Hotel. E, em Lagos, a sede local da Legião Portuguesa é hoje o Hotel Casa da Moura.

\section{“PoRTUgal PAÍs DE TURISMo" COM POUCA MEMóRIA}

As prisões políticas da ditadura e as sedes e delegações da polícia política, em particular, são locais com uma estreita relação com o sofrimento. É inegável que as prisões,

\footnotetext{
${ }^{16}$ Retirado de http://www.monumentos.pt/Site/APP_PagesUser/SIPA.aspx?id=16363

17 Retirado de http://www.monumentos.pt/Site/APP_PagesUser/SIPA.aspx?id=16363

${ }^{18}$ Retirado de http://www.cm-lisboa.pt/noticias/detalhe/article/tribunal-da-boa-hora-regressa-ao-patrimonio-da-justica

19 Retirado de http://www.monumentos.pt/Site/APP_PagesUser/SIPA.aspx?id=32962

${ }^{20}$ Retirado de http://www.monumentos.pt/Site/APP_PagesUser/SIPA.aspx?id=6072

${ }^{21}$ Retirado de http://www.monumentos.pt/Site/APP_PagesUser/SIPA.aspx?id=6072
} 
campos de concentração e locais de interrogatório da polícia política do Estado Novo eram locais onde o sofrimento - e por vezes a morte - aconteciam: "a polícia política usou a tortura sistematicamente, sendo essa a sua principal arma de "investigação'" (Caldeira et al., 2011, p. 117). A violência física, aliada às más condições e ao isolamento vividos nas prisões, era a principal forma de tortura usada pela polícia política em Portugal durante a ditadura (Caldeira et al., 2011).

Não obstante, essa ligação foi em muitos casos ignorada e/ou desvalorizada no património após o fim da ditadura. Em alguns casos, como o da prisão de Caxias, o do tribunal plenário de São João Novo no Porto e até recentemente o do tribunal plenário da Boa Hora em Lisboa, os edifícios mantiveram a função que já tinham no anterior regime político. Vários outros locais, como a cadeia do Aljube e a delegação da PIDE de Coimbra permaneceram sob posse do Estado e albergaram sucessivos serviços públicos e administrativos que obrigaram à descaracterização dos edifícios.

Verificamos ainda que existem vários edifícios ocupados por instituições do Estado Novo que atualmente estão transformados em estabelecimentos hoteleiros. Embora alguns, como é o caso do Luggage Hostel \& Suites na antiga delegação da PIDE em Coimbra e da Pousada de Lisboa nas instalações do Conselho de Ministros de Salazar, possam manter alguns aspetos físicos do seu passado, foram desmitificados ao serem transformados em locais de lazer, e a ausência de informação turística sobre esses aspetos da história dos edifícios faz com que o seu passado enquanto locais de violência e sofrimento seja apagado.

Existem ainda edifícios que permaneceram sem utilização ou chegaram ao estado de devolutos, o que é o sintoma mais claro da dificuldade dos sucessivos governos portugueses de lidar com o património da ditadura. Com efeito, este tipo de património constitui um desafio para a identidade nacional. O passado desconfortável que estes lugares representam arrisca atravessar o presente de formas disruptivas, podendo abrir divisões sociais (Macdonald, 2009).

Ao mesmo tempo, isto revela uma mudança nos critérios de seleção do património. Por causa das suas ligações ao passado contestado da ditadura, estes edifícios deixaram de ser considerados dignos de preservação para as gerações futuras e foram excluídos do conceito atual de património. À semelhança do que aconteceu em Nuremberga, em Portugal houve um esforço de desmitificação (MacDonald, 2009) do património do Estado Novo, ao convertê-lo em espaços de uso quotidiano dos cidadãos. Mesmo os edifícios que foram convertidos em unidades hoteleiras, e por isso dotados do carácter extraordinário que advém da utilização turística, foram desprovidos das características que identificavam o seu passado ligado à ditadura, quer fisicamente quer pela ausência de informação turística que detalhe essa ligação. No caso da sede da PIDE, na rua António Maria Cardoso em Lisboa, houve mesmo um esforço de apagamento do passado do edifício como local de aprisionamento, tortura, e sofrimento que se pode considerar bem-sucedido.

No entanto, também como aconteceu em Nuremberga, estes esforços não tiveram um sucesso completo nem permanente. 
Em Portugal, as ações de pressão para a criação de espaços de memória da resistência antifascista ganham corpo a partir de 2005. Várias iniciativas concentram-se no NAM - Movimento Cívico Não Apaguem a Memória!. Este movimento empreendedor de memória nasce de uma iniciativa espontânea de cidadãos em protesto contra a transformação da antiga sede da PIDE num condomínio de luxo22. Dessa iniciativa surgem, primeiro, um abaixo-assinado por mais de 50 antigos presos políticos e depois uma petição com mais de seis mil assinaturas que exigiam a aprovação de uma

lei quadro que assegure a criação de espaços museológicos nacionais, onde a memória da resistência à ditadura, e da luta pela liberdade democrática, seja um legado de saber político e pedagogia cívica, em favor das futuras gerações. ${ }^{23}$

A petição, apresentada à Assembleia da República por Mário Soares, ex-Presidente da República e antigo preso político e Marques Junior, deputado e capitão de Abril, teve acolhimento e deu origem à Resolução da Assembleia da República $n^{\circ}$. 24/2008. Esta Resolução recomenda ao Governo, logo no seu ponto 1, a criação de um "museu da liberdade e da resistência" na cadeia do Aljube, em Lisboa, bem como a "valorização e apoio ao Museu da Resistência instalado na Fortaleza de Peniche" (Resolução da Assembleia da República n.o 24/2008, 2008). A resolução recomenda a implementação de museus e memoriais em locais relacionados com a memória da luta antifascista em Portugal, em particular na cadeia do Aljube, em Lisboa, a criação de condições de estímulo e concretização para os diversos projetos autárquicos e civis de musealização e construção de memoriais relativos à resistência à ditadura e, no seu ponto 2, a

constituição de um roteiro nacional da liberdade e da resistência, através dos lugares e de edifícios símbolo considerados de interesse nacional, no âmbito da resistência e da luta pela liberdade, incluindo, naturalmente, aqueles que são referências importantes na vitória da Revolução de 25 de Abril de 1974, e, se possível, a adopção de medidas de preservação e seu aproveitamento, nos casos mais adequados, como espaços de conservação, investigação e divulgação da memória histórica. (Resolução da Assembleia da República $n^{\circ} 24 / 2008,2008$ )

Um dos poucos resultados concretos desta resolução foi a criação do Museu do Aljube, em Lisboa. Trata-se de um museu que integra como elemento central da sua identidade museológica o seu passado enquanto prisão política e local de sofrimento. O Museu do Aljube assume como objetivos a educação dos visitantes e a preservação de memórias e testemunhos sobre o período de ditadura em Portugal e as ações de resistência ${ }^{24}$. Os relatos, testemunhos, e imagens de morte e de sofrimento presentes no

\footnotetext{
${ }^{22}$ Retirado de http://maismemoria.org/mm/home/historia/

${ }^{23}$ Retirado de http://maismemoria.org/mm/home/historia/

${ }^{24}$ Retirado de https://www.museudoaljube.pt/sobre-o-museu/
} 
museu, bem como a presença física do local contribuem para aumentar a intensidade de relacionamento com a morte e o sofrimento. Ao mesmo tempo potenciam a reflexão sobre estes episódios de morte e de sofrimento e o contexto em que ocorreram bem como a sua projeção em diferentes tempos. Não obstante este conteúdo, o percurso expositivo do Museu do Aljube termina com a mensagem de vitória da democracia, reforçando uma identidade nacional positiva.

Apesar de a Resolução da Assembleia da República n. ${ }^{\circ}$ 24/2008 especificar a necessidade de valorização e apoio ao Núcleo da Resistência no Museu Municipal de Peniche, este local esteve em vias de ser concessionado a privados pelo Estado menos de uma década depois. Valeu aqui mais uma vez a intervenção dos empreendedores de memória, que conseguiram usar a contestação pública em favor da preservação e memorialização de um dos maiores símbolos do sistema prisional da ditadura e da resistência em Portugal.

Ao contrário da identidade mais precisa do Museu do Aljube como museu de resistência, o museu que funcionava na Fortaleza de Peniche englobava aspetos da história e cultura municipais além do núcleo de resistência, apresentando uma identidade dissonante. A dissonância era ainda agravada pela presença, no mesmo espaço, de equipamentos municipais de lazer.

O museu que funciona na delegação da PIDE do Porto é um caso curioso, porque apesar de não estar orientado para o seu passado enquanto centro de detenção e tortura da PIDE mantém uma ligação à morte e ao sofrimento ao ser um museu militar. Esta ligação contudo é relativamente ténue e menos intensa do que seria caso o museu se configurasse em torno do seu passado como delegação da polícia política. As várias funções do edifício ao longo do tempo - residência familiar, delegação da PIDE, museu militar - têm o potencial de lhe conferir um elevado grau de dissonância.

A diversidade de funções desempenhadas por todos estes edifícios antes, durante, e depois da ditadura é uma fonte de dissonância. Todavia, a maior causa de dissonância é sua ligação ao aparelho repressivo e ideológico do regime ditatorial: "todos os locais de dor e vergonha revelam dissonâncias, pois existem sempre perpetradores e vítimas e as suas perspetivas inevitavelmente diferem radicalmente" (Logan \& Reeves, 2009, p. 3).

\section{ConCLUSÕES}

O património é uma criação contemporânea, porém cada geração deixa património à geração seguinte. Cabe às gerações seguintes lidar com esse património e reconciliar-se com ele, integrá-lo ou intervir nele. Contudo, o património é um conceito em fluxo e pleno de tensões (Tunbridge \& Ashworth, 1996).

O alargamento da definição de património permitiu a inclusão dos lugares relacionados com aspetos desagradáveis da história dos povos e dos locais. Porém torna-se necessário construir uma nova base filosófica para essa definição, pois se todas as formas de comportamento social fazem parte da cultura, a gestão do seu património requer o estabelecimento de limites e perspetivas (Logan \& Reeves, 2009). 
Long e Reeves (2009, p. 78) afirmam que "o propósito da preservação de património no caso de lugares de dor e vergonha é o de comemorar as vítimas" e que "há pouco espaço para a preservação de sítios dos perpetradores". No entanto nem sempre é fácil fazer esta distinção. As prisões políticas, por exemplo, podem ser encaradas simultaneamente como locais de opressão e de resistência. Além disso, a simples ação de memorialização deste tipo de património pode incentivar a glorificação dos perpetradores por aqueles que se identificam com eles ou os seus motivos (Tunbridge \& Ashworth, 1996).

A interpretação deste tipo de património à luz do turismo negro representa uma oportunidade para decisores e visitantes. A presença da morte e do sofrimento no conteúdo interpretativo dos lugares confere-lhes um carácter extraordinário que potencia a desestabilização de premissas culturais e identitárias e dos emaranhamentos sobre memória e identidade em diferentes tempos. No entanto, para que essa interpretação seja possível é necessário que a ligação dos edifícios do Estado Novo à morte e ao sofrimento não seja apagada com o seu uso turístico.

A análise dos usos atuais do principal património do Estado Novo demonstra que vários dos edifícios mais emblemáticos desse regime têm atualmente um uso turístico. Contudo na maioria dos casos esse uso foi ganho com a perda ou até o apagamento das características que ligavam os locais ao seu passado negro durante a ditadura.

Pode-se argumentar que não é possível que todos os lugares relacionados com a memória da ditadura e da resistência antifascista em Portugal sejam memorializados ou sequer preservados. No entanto o apagamento dos aspetos considerados desagradáveis da história dos locais não é a única alternativa à musealização. Mesmo nos locais cujo foco é o entretenimento ou o relaxamento, como os hotéis em que foram transformados alguns dos edifícios do Estado Novo, seria possível existir informação turística sobre o seu passado ligado à morte e ao sofrimento. A informação não se limita aos painéis físicos nos edifícios: ela pode estar presente em roteiros turísticos nos quais a interpretação é feita por guias, quer humanos quer com recurso a tecnologia - desde os tradicionais guias em papel até à realidade aumentada. Esta apresenta uma grande oportunidade interpretativa quando os edifícios cumprem hoje funções muito diferentes daquela(s) que cumpriam no período da ditadura.

O fator decisivo na criação dos museus e memoriais da resistência antifacista em Portugal parece ser a ação dos grupos empreendedores de memória, como a URAP ou o NAM. Apesar das indagações oficiais e resoluções de órgãos do Governo, foi a contestação popular, não só mas também organizada naqueles movimentos, que despoletou ações concretas de preservação e musealização de vários espaços ligados ao Estado Novo.

Ainda assim, continua a existir apenas um museu da resistência em Portugal, na cadeia do Aljube. O futuro Museu Nacional da Resistência e Liberdade, a instalar no Forte de Peniche, será um passo importante na preservação da memória do combate ao regime ditatorial português, mas o sonhado Roteiro Nacional da Memória da Resistência e da Liberdade permanece, em larga medida, circunscrito ao texto da Resolução da Assembleia da República n. ${ }^{\circ}$ 24/2008. 
Seria interessante que investigações futuras apurassem que outras iniciativas de memorialização e uso turístico de património material e imaterial ligado ao Estado Novo e à resistência antifascista poderão estar em curso em Portugal e noutros países anteriormente ocupados por este. Que narrativas estarão na base destas iniciativas?

Esta investigação abriu-nos uma indagação ainda mais ampla: como é que este e outros aspetos desagradáveis da história de Portugal, como a escravatura, a Inquisição, o Colonialismo, são incorporados pelo Turismo? A tese de doutoramento em que esta investigação se insere não fornecerá respostas inequívocas a estas perguntas, mas irá contribuir para o leque do conhecimento sobre o turismo em locais de morte e de sofrimento em Portugal, ao debruçar-se sobre a atividade turística no Museu do Aljube a partir do olhar teórico e metodológico dos Estudos Culturais.

\section{FinANCIAMENTO}

Este trabalho insere-se na investigação de Doutoramento em Estudos Culturais UA/UM intitulada "Turismo e Morte: mediação, discursos, e tecnologias de linguagem" e financiada pela Fundação para a Ciência e a Tecnologia (ref. ${ }^{a}$ SFRH/BD/101121/2014) que decorre sob orientação da Professora Doutora Maria Manuel Baptista (UA) e coorientação dos Professores Doutores José Eduardo Rebelo (UA) e Moisés de Lemos Martins (UM).

\section{REFERÊNCIAS}

Agência Lusa. (2018a). Antigo Tribunal da Boa Hora pode vir a receber Tribunal da Relação de Lisboa. Retirado de https://www.publico.pt/2018/05/23/sociedade/noticia/ antigo-tribunal-da-boa-hora-pode-vir-a-receber-tribunal-da-relacao-de-lisboa-1831278

Agência Lusa. (2018b). Cascais abre forte de Santo António de cara lavada para celebrar democracia. Retirado de https://www.dn.pt/lusa/interior/cascais-abre-forte-de-santo-antonio-de-cara-lavada-para-celebrardemocracia-9282458.html

Alves, M. (2017, janeiro). O Estado Novo está como novo. Sábado. Retirado de http://www.sabado.pt/ portugal/detalhe/o-estado-novo-esta-como-novo

Belo, I. (2016). Hámuitashistórias paracontarnoAntigo PresídiodaTrafaria.Visão.Retiradodehttp://visao.sapo.pt/ actualidade/visaose7e/sair/2016-11-05-Ha-muitas-historias-para-contar-no-Antigo-Presidio-da-Trafaria

Caldeira, A., Rosas, F., Quintanilha, I., Pimentel, I. \& Martins, S. (Eds.) (2011). Aljube: a voz das vítimas. Lisboa: INCM - Imprensa Nacional Casa da Moeda.

Chaves, S. (2015, junho). Pousada de Lisboa já abriu. Sábado. Retirado de https://www.sabado.pt/gps/ detalhe/pousada-de-lisboa-ja-abriu

Duffy, T. (2001). Museums of "human suffering" and the struggle for human rights. Museum International, 53(1), 10-16. Retirado de http://onlinelibrary.wiley.com/doi/10.1111/1468-0033.00292/full

Ferreira, A. S. (2018). Estado de abandono. Linha da Frente (XX), ep. 5. Retirado de https://www.rtp.pt/play/ p4231/e330175/linha-da-frente 
Festinger, L. (1957). A theory of cognitive dissonance. Stanford: Stanford University Press. Retirado de https:// books.google.pt/books?id=voeQ-8CASacC\&printsec=frontcover\&hl=pt-PT\#v=onepage\&q\&f=false

Forest, B. \& Johnson, J. (2001). Unraveling the threads of History. Annals of the Association of American Geographers, 92(3). Retirado de http://www.dartmouth.edu/ crn/crn_papers/Forest-Johnson.pdf

Foucault, M. (1984). De outros espaços (1967), Heterotopias. Architecture, Mouvemente, Continuité, 5, 46-49.

Logan, W. \& Reeves, K. (2009). Introduction: remembering places of pain and shame. In W. Logan \& K. Reeves (Eds.), Places of pain and shame: dealing with "difficult heritage" (pp. 1-14). Milton Park: Routledge.

Long, C. \& Reeves, K. (2009). Dig a hole and bury the past in it: Reconciliation and the heritage of genocide in Cambodia. In W. Logan \& K. Reeves (Eds.), Places of pain and shame: dealing with "difficult heritage" (pp. 68-81). Milton Park: Routledge.

Macdonald, S. (2009). Difficult heritage. Londres e Nova lorque: Routledge.

Martins, A. R. (2015). A musealização de heranças dificeis: o caso do Museu do Aljube - Resistência e Liberdade. Dissertação de Mestrado, Universidade Nova de Lisboa, Lisboa, Portugal. Retirado de https://run.unl. pt/handle/10362/18144

Martins, M. L. (2002). O trágico na Modernidade. Interact, 5. Retirado de http://www.interact.com.pt/ interact5/default.htm

Martins, M. L. (2013). O corpo morto: mitos, ritos e superstições. Revista Lusófona de Estudos Culturais/ Lusophone Journal of Cultural Studies, 1(1), 109-134.

Miles, W. F. S. (2002). Auschwitz: museum interpretation and darker tourism. Annals of Tourism Research, 29(4), 1175-1178. DOI: 10.1016/S0160-7383(02)00054-3

Nora, P. (1993). Entre história e memória, a problemática dos lugares. Projeto História 10, 7-28.

Oliveira, E. (2012). Aljube: uma cadeia política. Dissertação de Mestrado, Universidade Nova de Lisboa. Lisboa, Portugal. Retirado de https://run.unl.pt/handle/10362/9390

Pacheco, N. (2006). Os tribunais plenários e a memória necessária. Público. Retirado de https://www. publico.pt/2006/12/06/jornal/os-tribunais-plenarios-e-a-memoria-necessaria-110903

Ray, L. (2006). Mourning, melancholia and violence. In D. Bell (Ed.), Memory, Trauma and world politics: reflections on the relationship between past and present (pp. 135-154). Nova lorque: Palgrave Macmillan.

Resolução da Assembleia da República n. ${ }^{\circ}$ 24/2008, Diário da República 1. ${ }^{a}$ série - N. ${ }^{\circ} 122$ (2008). Lisboa: Assembleia da República. Retirado de https://dre.pt/application/conteudo/456226

Sede da PIDE à venda por dois milhões de euros. (2013). tvi24. Retirado de http://www.tvi24.iol.pt/ sociedade/coimbra/sede-da-pide-a-venda-por-dois-milhoes-de-euros

Sharpley, R. (2009). Shedding light on dark tourism: an introduction. In R. Sharpley \& P. R. Stone (Eds.), The darker side of travel: the theory and practice of dark tourism (pp. 3-32). Londres: Channel View Publications.

Sharpley, R. \& Stone, P. R. (Eds.) (2009). The darker side of travel: the theory and practice of dark tourism. Bristol: Channel View Publications.

Silva, E. P. da. (2000). Património e identidade. Os desafios do turismo cultural. Antropológicas, 4, 217-224. Retirado de https://revistas.rcaap.pt/antropologicas/article/view/932 
Simões, B. (2016). Quatro anos depois, o Tribunal da Boa Hora vai ter uma escola. Jornal de Negócios. Retirado de https://www.jornaldenegocios.pt/economia/educacao/detalhe/ quatro_anos_depois_o_tribunal_da_boa_hora_vai_ter_uma_escola

Stone, P. R. (2006). A dark tourism spectrum: towards a typology of death and macabre related tourist sites, attractions and exhibitions. Tourism, 54(2), 145-160.

Stone, P. R. (2011). Dark tourism in contemporary society: mediating life and death narratives. Retirado de http://works.bepress.com/philip_stone/29/

Stone, P. R. (2013). Dark tourism, heterotopias and post-apocalyptic places: the case of Chernobyl. In L. White \& E. Frew (Eds.), Dark tourism and place identity: managing and interpreting dark places (pp. 79-93). Melbourne: Routledge.

Tribunal de São João Novo no Porto está a cair (2018). RTP. Retirado de https://www.rtp.pt/noticias/pais/ tribunal-de-sao-joao-novo-no-porto-esta-a-cair_v1061116

Tunbridge, J. E. \& Ashworth, G. (1996). Dissonant heritage: the management of the past as a resource in conflict. Chichester: John Wiley and Sons.

Walter, T. (2009). Dark tourism: mediating between the dead and the living. In R. Sharpley \& P. R. Stone (Eds.), The darker side of travel: the theory and practice of dark tourism (pp. 39-55). Bristol: Channel View Publications.

\section{NOTAS BIOGRÁFICAS}

Belmira Coutinho. Doutoranda em Estudos Culturais pelas Universidades de Aveiro e do Minho. Mestre em Gestão e Planeamento em Turismo pela Universidade de Aveiro e licenciada em Turismo pela Universidade do Algarve. Investigadora do Centro de Estudos de Comunicação e Sociedade da Universidade do Minho. A sua tese de doutoramento (em curso), financiada pela Fundação para a Ciência e a Tecnologia (FCT), aborda os discursos e as narrativas de morte e de sofrimento em prisões políticas da ditadura portuguesa transformadas em Museus de Resistência.

Email: belmira.coutinho@ua.pt

Morada: Departamento de Línguas e Culturas, Universidade de Aveiro, Campus Universitário de Santiago 3810-193 Aveiro Portugal

Maria Manuel Baptista. Professora Catedrática e investigadora em Estudos Culturais da Universidade de Aveiro e Directora do Programa Doutoral em Estudos Culturais da Universidade de Aveiro ( $3 .^{\circ}$ ciclo lecionado em colaboração com a Universidade do Minho). Dirige atualmente o grupo de Investigação em Género e Performances e o Núcleo de Estudos em Cultura e Ócio do Centro de Línguas, Literatura e Culturas da Universidade de Aveiro. Com obra diversa, publicada nacional e internacionalmente, na área dos Estudos Culturais, é agregada em Estudos Culturais pela Universidade do Minho desde 2013, doutorada em Cultura, pela Universidade de Aveiro, em 2002. Começou a sua atividade profissional em 1986 como jornalista e desde então lecionou e conduziu investigação em Estudos Culturais, nas áreas de interseção entre as Ciências Humanas e Sociais e os Estudos Artísticos. 


\section{Email: mbaptista@ua.pt}

Morada: Departamento de Línguas e Culturas, Universidade de Aveiro Campus Universitário de Santiago 3810-193 Aveiro Portugal

Moisés de Lemos Martins Professor catedrático do Departamento de Ciências da Comunicação e diretor do Centro de Estudos de Comunicação e Sociedade (CECS), no Instituto de Ciências Sociais (ICS) da Universidade do Minho. É diretor do Centro de Estudos de Comunicação e Sociedade da Universidade do Minho e das revistas Comunicação e Sociedade e Revista Lusófona de Estudos Culturais/ Lusophone Journal of Cultural Studies do referido centro. Fez a licenciatura em Sociologia na Universidade de Ciências Humanas de Estrasburgo e aí continuou até ao doutoramento, em 1984. É autor de numerosos artigos e publicações em Portugal e no estrangeiro, nomeadamente sobre Semiótica Social e da Sócio-antropologia da Comunicação, e dos seus livros destacam-se títulos como Crise no castelo da cultura (2011), A linguagem, a verdade e o poder (2002), Para uma inversa navegação - o discurso da identidade (1996) e O olho de Deus no discurso salazarista (1990).

Email: moiseslmartins@ics.uminho.pt

Morada: Centro de Estudos de Comunicação e Sociedade, ICS, Universidade do Minho, Campus de Gualtar, 4710-057, Braga, Portugal

José Eduardo Rebelo Professor Auxiliar com Agregação no Departamento de Biologia da Universidade de Aveiro, onde tem desenvolvido intensa atividade de pesquisa, integrada em projetos nacionais e internacionais, em domínios da Biodiversidade e Evolução Animal e da Ecologia Marinha. Tem lecionado na Universidade de Hull (Inglaterra), Universidade de Montpellier (França), Universidade das Antilhas e da Guiana (Guadalupe) e Universidade Federal Rural do Rio de Janeiro (Brasil). Em paralelo desenvolve investigação na área do luto, tendo já publicado várias obras sobre o tema, tais como "Desatar o Nó do Luto" (2004), "Amor, Luto e Solidão" (2009), e "Defilhar: como viver a perda de um filho" (2013). É fundador da APELO - associação de apoio ao luto de pessoas, famílias e comunidades, Presidente do Espaço do Luto, Coordenador do Observatório do Luto em Portugal, e Vice-Presidente da SPEIL - Sociedade Portuguesa de Estudo e Intervenção no Luto.

Email: rebelo@ua.pt

Morada: Departamento de Biologia, Universidade de Aveiro Campus Universitário de Santiago 3810-193 Aveiro Portugal

\section{* Submetido: 28-02-2018 \\ * Aceite: $22-07-2018$}

